\title{
Risk factors for peritonitis in patients on continuous ambulatory peritoneal dialysis who undergo colonoscopy: a retrospective multicentre study
}

Tae-Geun Gweon ${ }^{1}$, Sung Hoon Jung ${ }^{1,2^{*}}$ (D), Sang Woo Kim¹, Kang-Moon Lee ${ }^{1}$, Dae Young Cheung ${ }^{1}$, Bo-In Lee ${ }^{1}$ and Hwang Choi ${ }^{1}$

\begin{abstract}
Background: Colonoscopy is associated with a risk of peritonitis in patients on peritoneal dialysis. However, no study has yet described the risk factors in play.

Methods: This was a retrospective multicentre study. The medical records of patients on continuous ambulatory peritoneal dialysis (CAPD) who underwent colonoscopy from January 2003 to December 2012 were analysed. We recorded demographic characteristics, colonoscopic factors, use of prophylactic antibiotics, and development of peritonitis. Colonoscopy-related peritonitis was defined as peritonitis developing within 1 week after colonoscopy. Demographic and clinical characteristics were compared between patients who did and those who did not develop peritonitis.

Results: During the study period, 236 patients on CAPD underwent colonoscopy, of whom 9 (3.8\%) developed peritonitis. The rates of polypectomy/endoscopic mucosal resection were significantly higher in the peritonitis group than in the no peritonitis group (66.7 vs. $23.4 \%, p=0.009$ ). Prophylactic antibiotics were prescribed before colonoscopy in 65 patients; none developed peritonitis. No patient who developed peritonitis received prophylactic antibiotics $(p=0.067)$.
\end{abstract}

Conclusions: Advanced procedures including polypectomy or endoscopic mucosal resection increase colonoscopy-related peritonitis in patients on CAPD. Randomized controlled trials to investigate whether prophylactic antibiotics are needed to prevent peritonitis in all CAPD patients are warranted.

Keywords: Peritoneal dialysis, Continuous ambulatory peritoneal dialysis, Colonoscopy, Peritonitis

\section{Introduction}

Peritoneal dialysis (PD) is a major form of renal replacement. Peritonitis is an important complication associated with technical failure and death, as well as an important quality measure, in patients on PD. [1-4] The International Society for Peritoneal Dialysis recommends an annual peritonitis rate of less than 0.5 episodes per year [5]. Risk factors for PD-related peritonitis are older age,

\footnotetext{
* Correspondence: shjung74@catholic.ac.kr

'Division of Gastroenterology, Department of Internal Medicine, College of Medicine, The Catholic University of Korea, Seoul, Republic of Korea

${ }^{2}$ Department of Internal Medicine, College of Medicine, Eunpyeong St. Mary's Hospital, The Catholic University of Korea, Seoul, Republic of Korea
}

diabetes, hypoalbuminemia, and invasive procedures including hysteroscopy, dental procedures, and colonoscopy [5-9].

As most gut microorganisms are found in the colon, the gut is a potential source of intra-abdominal infection [10]. Several studies have reported the development of peritonitis after colonoscopy in patients on PD. [11, 12] Recently, the American Society of Gastrointestinal Endoscopy and the International Society for Peritoneal Dialysis recommended that prophylactic antibiotics be prescribed before colonoscopy for such patients [5, 13]. However, little evidence supports this recommendation. One study found that the rate of peritonitis was $6.4 \%$ in $\mathrm{PD}$ patients undergoing

(c) The Author(s). 2019 Open Access This article is distributed under the terms of the Creative Commons Attribution 4.0 International License (http://creativecommons.org/licenses/by/4.0/), which permits unrestricted use, distribution, and 
endoscopy [14]. However, the cited work included patients undergoing upper endoscopy and hysteroscopy as well as colonoscopy [14]. Moreover, previous studies could not identify factors contributing to colonoscopy-related peritonitis because of a small sample size $[12,14,15]$. In this multicentre study, we sought to identify factors associated with peritonitis and the effects of antibiotic prophylaxis in patients on PD undergoing colonoscopy.

\section{Materials and methods}

\section{Study population and methods}

This was a multicentre, retrospective, cohort study. The medical records of patients on continuous ambulatory peritoneal dialysis (CAPD) who underwent colonoscopy from January 2003 to December 2012 were analysed. Patients were treated in seven hospitals of the Catholic University of Korea: Incheon St Mary's Hospital, Vincent Hospital, Bucheon St. Mary's Hospital, Yeouido St. Mary's Hospital, Uijeongbu St. Mary's Hospital, and Seoul St. Mary's Hospital. The study protocol was approved by the institutional review board of each participating hospital. Written informed consent was waived because the work was retrospective in nature. We recorded demographic characteristics and colonoscopyrelated factors, including the indication for colonoscopy, bowel preparation quality, biopsy status, and the need for advanced procedures including polypectomy or endoscopic mucosal resection (EMR) during colonoscopy. The use of prophylactic antibiotics was assessed. All patients ingested 4L of PEG (Colyte, Taejoon Pharma, Seuol, Korea). Patients were divided into the peritonitis and no peritonitis groups. In those who developed colonoscopy-related peritonitis, the results of peritoneal fluid culture and antibiotic treatment, and the clinical outcomes, were investigated.

\section{Definitions}

Colonoscopy-related peritonitis was defined as peritonitis developing within 1 week after colonoscopy. Peritonitis was diagnosed when at least two of the following criteria were met: (1) abdominal pain with or without a cloudy dialysis effluent, (2) a peritoneal effluent white cell count $>100 / \mu \mathrm{L}$ with $>50 \%$ polymorphonuclear neutrophils, and (3) a positive dialysis effluent culture [5].

\section{Statistical analysis}

Continuous variables are presented as means \pm standard deviations and were compared using Student's $t$-test or the Mann-Whitney U-test. Categorical variables are presented as numbers with percentages and were compared using the chi-squared or Fisher's exact test. Demographic and clinical characteristics were compared between patients who did and those who did not develop peritonitis. A $p$-value $<0.05$ was considered significant. All statistical analyses were performed using SAS ver. 9.0 software (SAS Institute, Cary, NC).

\section{Results}

\section{Baseline characteristics of the study subjects}

During the study period, 236 patients on CAPD underwent colonoscopy after removing dialysate, of whom 9 (3.8\%) developed peritonitis. The patient baseline characteristics are listed in Table 1 . Sex, age, and body mass index were comparable between the two groups. The diabetes rates were $33.3 \%$ in the peritonitis group and $37.4 \%$ in the no peritonitis group $(p=1.000)$. The CAPD durations were 33.9 and 51.4 months, respectively. The screening colonoscopy rates were $55.6 \%$ in the peritonitis group and $60.4 \%$ in the no peritonitis group $(p=0.744)$.

Table 1 Baseline characteristics

\begin{tabular}{|c|c|c|c|}
\hline Characteristics & Peritonitis $(n=9)$ & No peritonitis $(n=227)$ & $P$ \\
\hline Male, n (\%) & $5(55.6)$ & $123(54.2)$ & 1.000 \\
\hline Age, years ( $\pm S D$ ) & $52.6( \pm 11.1)$ & $50.4( \pm 16.7)$ & 0.061 \\
\hline $\mathrm{BMI}, \mathrm{kg} / \mathrm{m}^{2}( \pm \mathrm{SD})$ & $24.3( \pm 2.2)$ & $24.2( \pm 3.3)$ & 0.796 \\
\hline Etiology of ESRD & & & 1.000 \\
\hline Diabetes, n (\%) & $3(33.3)$ & $85(37.4)$ & \\
\hline Non-diabetes, n (\%) & $6(66.7)$ & $142(62.6)$ & \\
\hline Duration of CAPD, months & $33.9 \pm 25.5$ & $51.4 \pm 53.7$ & 0.207 \\
\hline \multicolumn{4}{|l|}{ Indication for colonoscopy } \\
\hline Screening, n (\%) & $5(55.6)$ & $137(60.4)$ & 0.744 \\
\hline Non-screening, n (\%) & $4(44.4)$ & $90(39.6)$ & \\
\hline
\end{tabular}

SD standard deviation, ESRD end stage renal disease, CAPD continuous ambulatory peritoneal dialysis 


\section{Colonoscopic factors and the use of prophylactic antibiotics}

The results of colonoscopy are shown in Table 2. Neither the experience of expert or trainee nor bowel preparation quality differed between the two groups. The colonic mucosa was manipulated/biopsied, and advanced procedures such as polypectomy or EMR performed, in 123 patients. The extent of colonic mucosal manipulation was higher in the peritonitis group than in the no peritonitis group (88.9 vs. $50.7 \%, p=0.037$ ). Colonic mucosal biopsy did not increase the rate of peritonitis development (peritonitis vs. no peritonitis group: $22.2 \%$ vs. $27.3 \%, p=1.000$ ). There was no association between the size of polyps and the infection rate in polypectomy/EMR (peritonitis vs. no peritonitis group: $0.97 \mathrm{~cm}$ vs $0.96 \mathrm{~cm}, p=0.962$ ). However, the rates of polypectomy/EMR were significantly higher in the peritonitis group than in the no peritonitis group (66.7 vs. 23.4, $p=0.009$ ). Prophylactic antibiotics were prescribed before colonoscopy to 65 patients (27.5\%), and none of these patients developed peritonitis. However, the proportion of patients who received prophylactic antibiotics prior to colonoscopy did not differ significantly between the two groups (peritonitis vs. no peritonitis group: 0 vs. 28.6\%; $p=0.067$ ). In a subgroup analysis, of the 59 patients who underwent polypectomy or EMR, prophylactic antibiotics were given to 14 (23.7\%). Although none of the six patients who developed peritonitis after polypectomy or EMR received prophylactic antibiotics, such antibiotics did not prevent peritonitis statistically (peritonitis vs. no peritonitis group: 0 [0/6 vs. group $26.4 \%$ [14/53], $p=0.319$ ).

\section{Clinical outcomes}

The details of the peritonitis cases are listed in Table 3. The microorganisms isolated from peritoneal effluent were Staphylococcus aureus $(n=1)$, Escherichia coli $(n=5)$, and none $(n=3)$. One patient who underwent no advanced procedure had S. aureus. All patients received at least two antibiotics. The PD catheter was removed from one patient 5 days after antibiotic treatment commenced. We recorded no mortalities.

\section{Discussion}

We sought to identify risk factors for colonoscopyassociated peritonitis in patients on CAPD. The overall peritonitis rate was $3.8 \%$. Both polypectomy and EMR were peritonitis risk factors. Although statistical significance was not attained $(p=0.067)$, peritonitis was absent in patients who received antibiotic prophylaxis prior to colonoscopy. To the best of our knowledge, this is the first multicentre study to explore the risk factors for colonoscopy-related peritonitis in patients on CAPD; we included the largest number of patients evaluated on this subject to date.

The principal causes of PD-related peritonitis are catheter infections, thus contamination of PD catheters and exit site and tunnel infections. Less often, microorganisms from the colon or vagina, or haematogenous dissemination after dental procedures, trigger peritonitis in patients on PD. $[16,17]$ We found that polypectomy and EMR were risk factors for peritonitis. The colonic mucosa prevents microorganism translocation and controls intestinal permeability $[18,19]$. Polypectomy and EMR create colonic mucosal defects facilitating translocation of intestinal microorganisms. We found that colonic biopsy was not associated with a risk of peritonitis. Such mucosal defects may be smaller than those caused by polypectomy or EMR. Also, we removed colon polyps electrically, thus not via cold snaring. Compared with cold-snare polypectomy, hot-snare polypectomy and EMR damage the large bowel wall to greater extents $[20,21]$. Thermal injury of the colonic mucosa may act synergistically with a mucosal defect to trigger peritonitis.

Table 2 Factors related to colonoscopy

\begin{tabular}{|c|c|c|c|}
\hline Characteristics & Peritonitis $(n=9)$ & No peritonitis $(n=227)$ & $P$ \\
\hline Colonoscopist, n (\%) & & & 0.505 \\
\hline Expert, n (\%) & $3(33.3)$ & $118(52.0)$ & \\
\hline Trainee, n (\%) & $6(66.7)$ & $109(48.0)$ & \\
\hline \multicolumn{4}{|l|}{ Bowel preparation quality $n(\%)$} \\
\hline Excellent or good & $9(100)$ & $216(95.2)$ & \\
\hline Fair & $0(0)$ & $11(4.8)$ & \\
\hline Colonoscopic procedure & $8(88.9)$ & $115(50.7)$ & 0.037 \\
\hline Colon biopsy, n (\%) & $2(22.2)$ & $62(27.3)$ & 1.000 \\
\hline Polypectomy / EMR, n (\%) & $6(66.7)$ & $53(23.4)$ & 0.009 \\
\hline Use of prophylactic anbitiobitcs, n (\%) & & & 0.067 \\
\hline Yes & $0(0)$ & $65(28.6)$ & \\
\hline No & $9(100)$ & $162(71.4)$ & \\
\hline
\end{tabular}

EMR endoscopic mucosal resection 
Table 3 Details of peritonitis

\begin{tabular}{lllllll}
\hline Patient number & Sex & Age & Procedure & Culture & Treatment & Outcome \\
\hline 1 & Female & $20-30$ & Colon biopsy & No growth & Cefazolin + gentamycin & Recovered \\
2 & Male & $30-40$ & EMR & No growth & Cefazolin + gentamycin & Recovered \\
3 & Male & $30-40$ & Polypectomy & E. coli & Vancomycin + ceftazidime & Recovered \\
4 & Male & $40-50$ & EMR & E. coli & Cefamezine + tobramycin & Recovered \\
5 & Female & $50-60$ & EMR & No growth & Cefamezin + gentamycin & Recovered \\
6 & Male & $50-60$ & EMR & E. coli & Cefamezin + gentamycin & Recovered \\
7 & Male & $60-70$ & Polypectomy & E. coli & Cefazolin + gentamycin & Recovered \\
8 & Female & $60-70$ & Colon biopsy & E. coli & Ceftazidime + metronidazole & Recovered \\
9 & Female & $70-80$ & No procedure & S. aureus & Cefazolin + gentamycin & Catheter removal \\
\hline
\end{tabular}

$E M R$ endoscopic mucosal resection

Of the 113 patients who did not undergo mucosal manipulation, peritonitis occurred in only $1(0.8 \%)$. The causative organism was $S$. aureus. The causative organism depends on the infection site. Usually, Gram-positive bacteria cause catheter-related infections. However, Gramnegative bacteria are commonly translocated from the colon or vagina [5]. S. aureus is the most common causative agent of catheter-related peritonitis [16]; we could not exclude the possibility of catheter-related peritonitis in the abovementioned patient. Peritonitis resolved after catheter removal.

Were prophylactic antibiotics useful? Of the 236 patients, only 65 received such antibiotics. The overall peritonitis rate after colonoscopy was $3.8 \%$. When we divided the patients into those who received prophylactic antibiotics and those who did not, the peritonitis rates were $0(0 / 65)$ and $5.3 \%(9 / 171)$, respectively. Although statistical significance was not attained $(p=0.067)$, peritonitis did not develop in any patient who received prophylactic antibiotics, in line with the findings of previous studies [12,14]. Most studies found that the use of prophylactic antibiotics did not attain statistical significance in terms of peritonitis development. It is unethical to give patients placebos. We included patients on CAPD who underwent colonoscopy from 2003 to 2012, of whom a relatively small proportion (27.5\%) received antibiotics prior to colonoscopy. We gave antibiotics prior to colonoscopy from 2010. Colonic neoplasms are found in up to $50 \%$ of patients undergoing colonoscopy [22-25]. Although diagnostic colonoscopy lacking a therapeutic procedure may not cause peritonitis, physicians cannot predict the presence of colon polyps. Therefore, prophylactic antibiotics should be given to all patients on CAPD prior to colonoscopy.

Our study had several strengths. First, this is the first multicentre study to explore whether colonoscopy triggers peritonitis in patients on PD. Second, we investigated factors causing peritonitis and identified advanced procedures such as polypectomy and EMR as triggers.
Several limitations of the study should be addressed. The work was retrospective in nature. Some data were lacking. Colonoscopy procedure time, which might affect peritonitis development, was not recorded. We did not include patients on automated PD (APD), but rather only CAPD patients. Peritoneal fluid triggers peritonitis. As patients on APD do not retain peritoneal fluid during the day, we hypothesized that patients on CAPD are at a higher risk of colonoscopy-related peritonitis than are patients on APD; thus, our findings may not be applicable to patients on APD. In addition, we just surveyed the use of prophylactic antibiotics, not antibiotic regimens. Further studies of prophylactic antibiotic regimens are needed to prevent colonoscopy-related peritonitis in CAPD patients.

\section{Conclusions}

Advanced procedures including polypectomy and EMR increase the risk of colonoscopy-associated peritonitis in patients on CAPD. Randomized controlled trials to investigate whether prophylactic antibiotics are needed to prevent peritonitis in all CAPD patients are warranted.

\section{Abbreviations}

CAPD: Continuous ambulatory peritoneal dialysis; EMR: Endoscopic mucosal resection; PD: Peritoneal dialysis

\section{Acknowledgements}

Not applicable

\section{Author's contributions}

SHJ, KML and HC planned and designed the review. SWK, DYC and BIL carried out data collection. Data analysis was performed by TGG under the supervision of SHJ. BIL and KML supervised the writing of the manuscript. All authors reviewed and approved the final draft of the manuscript.

\section{Funding}

Not applicable

\section{Availability of data and materials}

The datasets generated or analysed during the current study are available from the corresponding author on reasonable request. 


\section{Ethics approval and consent to participate}

This study was approved by the Institutional Review Board of the Catholic University of Korea (XC12RIMI0106V).

\section{Consent for publication}

Not applicable.

\section{Competing interests}

The authors declare that they have no competing interest.

Received: 7 June 2019 Accepted: 20 September 2019

Published online: 06 November 2019

\section{References}

1. Davenport A. Peritonitis remains the major clinical complication of peritoneal dialysis: the London, UK, peritonitis audit 2002-2003. Perit Dial Int. 2009;29(3):297-302.

2. Perez Fontan M, Rodriguez-Carmona A, Garcia-Naveiro R, Rosales M, Villaverde $P$, Valdes F. Peritonitis-related mortality in patients undergoing chronic peritoneal dialysis. Perit Dial Int. 2005;25(3):274-84.

3. Fried LF, Bernardini J, Johnston JR, Piraino B. Peritonitis influences mortality in peritoneal dialysis patients. J Am Soc Nephrol. 1996;7(10):2176-82.

4. Oliveira LG, Luengo J, Caramori JC, Montelli AC, Cunha Mde L, Barretti P. Peritonitis in recent years: clinical findings and predictors of treatment response of 170 episodes at a single Brazilian center. Int Urol Nephrol. 2012;44(5):1529-37.

5. Li PK, Szeto CC, Piraino B, de Arteaga J, Fan S, Figueiredo AE, Fish DN, Goffin E, Kim YL, Salzer W, et al. ISPD peritonitis recommendations: 2016 update on prevention and treatment. Perit Dial Int. 2016;36(5):481-508.

6. Nessim SJ, Bargman JM, Austin PC, Nisenbaum R, Jassal SV. Predictors of peritonitis in patients on peritoneal dialysis: results of a large, prospective Canadian database. Clin J Am Soc Nephrol. 2009:4(7):1195-200.

7. Okayama M, Inoue T, Nodaira Y, Kimura Y, Nobe K, Seto T, Sueyoshi K, Takane $\mathrm{H}$, Takenaka $\mathrm{T}$, Okada $\mathrm{H}$, et al. Aging is an important risk factor for peritoneal dialysis-associated peritonitis. Adv Perit Dial. 2012;28:50-4

8. Fan X, Huang $R$, Wang J, Ye H, Guo Q, Yi C, Lin J, Zhou Q, Shao F, Yu X, et al. Risk factors for the first episode of peritonitis in southern Chinese continuous ambulatory peritoneal dialysis patients. PLoS One. 2014;9(9):e107485.

9. Tian Y, Xie X, Xiang S, Yang X, Zhang X, Shou Z, Chen J. Risk factors and outcomes of high peritonitis rate in continuous ambulatory peritoneal dialysis patients: a retrospective study. Medicine. 2016;95(49):e5569.

10. Quigley EM. Gut bacteria in health and disease. Gastroenterol Hepatol. 2013; 9(9):560-9.

11. Ray SM, Piraino B, Holley J. Peritonitis following colonoscopy in a peritoneal dialysis patient. Perit Dial Int. 1990;10(1):97-8.

12. Yip T, Tse KC, Lam MF, Cheng SW, Lui SL, Tang S, Ng M, Chan TM, Lai KN, Lo WK. Risks and outcomes of peritonitis after flexible colonoscopy in CAPD patients. Perit Dial Int. 2007;27(5):560-4.

13. Committee ASoP, Khashab MA, Chithadi KV, Acosta RD, Bruining DH Chandrasekhara V, Eloubeidi MA, Fanelli RD, Faulx AL, Fonkalsrud L, et al. Antibiotic prophylaxis for Gl endoscopy. Gastrointest Endosc. 2015;81(1):81-9.

14. RWu HH, Li IJ, Weng CH, Lee CC, Chen YC, Chang MY, Fang JT, Hung CC, Yang CW, Tian YC. Prophylactic antibiotics for endoscopy-associated peritonitis in peritoneal dialysis patients. PLoS One. 2013;8(8):e71532.

15. Al-Hwiesh AK, Abdul-Rahman IS, Hussameldeen MA, Al-Audah N, Abdelrahman A, Moaigel HM, El-Salamony T, Noor AS, Al-Osail A, Al-Sayel D, et al. Colonoscopy in automated peritoneal dialysis patients: value of prophylactic antibiotics: a prospective study on a single antibiotic. Int J Artif Organs. 2017:40(10):550-7.

16. Szeto CC, Li PK, Johnson DW, Bernardini J, Dong J, Figueiredo AE, Ito $Y$, Kazancioglu R, Moraes T, Van Esch S, et al. ISPD catheter-related infection recommendations: 2017 update. Perit Dial Int. 2017;37(2):141-54.

17. Salzer WL. Peritoneal dialysis-related peritonitis: challenges and solutions. Int J Nephrol Renov Dis. 2018;11:173-86.

18. Lee $\mathrm{SH}$. Intestinal permeability regulation by tight junction: implication on inflammatory bowel diseases. Intestinal Res. 2015;13(1):11-8.

19. Oshima T, Miwa H. Gastrointestinal mucosal barrier function and diseases. J Gastroenterol. 2016;51(8):768-78.

20. Horiuchi A, Nakayama Y, Kajiyama M, Tanaka N, Sano K, Graham DY. Removal of small colorectal polyps in anticoagulated patients: a prospective randomized comparison of cold snare and conventional polypectomy. Gastrointest Endosc. 2014;79(3):417-23.
21. Ferlitsch M, Moss A, Hassan C, Bhandari P, Dumonceau JM, Paspatis G, Jover R, Langner C, Bronzwaer M, Nalankilli K, et al. Colorectal polypectomy and endoscopic mucosal resection (EMR): European Society of Gastrointestinal Endoscopy (ESGE) clinical guideline. Endoscopy. 2017:49(3):270-97.

22. Gweon TG, Kim SW, Noh YS, Hwang S, Kim NY, Lee Y, Lee SW, Lee SW, Lee JY, Lim CH, et al. Prospective, randomized comparison of same-day dose of 2 different bowel cleanser for afternoon colonoscopy: picosulfate, magnesium oxide, and citric acid versus polyethylene glycol. Medicine. 2015:94(13):e628.

23. Kwon SC, Choi SW, Choi SH, Park HS, Lee SH, Kim BG, Seo EH, Jang M, Ryu $\mathrm{SM}$, Kim DH, et al. The effect of Indigocarmine on improvement of the polyp detection rate during Colonoscopic examination with Hood cap. Intestinal Res. 2014;12(1):60-5.

24. Huh CW, Gweon TG, Seo M, Ji JS, Kim BW, Choi H. Validation of same-day bowel preparation regimen using $4 \mathrm{~L}$ polyethylene glycol: comparison of morning and afternoon colonoscopy. Medicine. 2018;97(37):e12431.

25. Lee SW, Chang JH, Ji JS, Maeong IH, Cheung DY, Kim JS, Cho YS, Chung WJ, Lee BI, Kim SW, et al. Effect of dynamic position changes on adenoma detection during Colonoscope withdrawal: a randomized controlled multicenter trial. Am J Gastroenterol. 2016;111(1):63-9.

\section{Publisher's Note}

Springer Nature remains neutral with regard to jurisdictional claims in published maps and institutional affiliations.
Ready to submit your research? Choose BMC and benefit from:

- fast, convenient online submission

- thorough peer review by experienced researchers in your field

- rapid publication on acceptance

- support for research data, including large and complex data types

- gold Open Access which fosters wider collaboration and increased citations

- maximum visibility for your research: over $100 \mathrm{M}$ website views per year

At BMC, research is always in progress.

Learn more biomedcentral.com/submissions 